\title{
A restrição combinatória e a multidimensionalidade do núcleo eventivo em unidades fraseológicas especializadas
}

\section{The selectional restriction and the multidimensionality of the eventive nucleus in specialized phraseological units}

Cleci Bevilacqua* Manuela Arcos**

\footnotetext{
* Universidade Federal do Rio Grande do Sul (UFRGS). Instituto de Letras. Departamento de Línguas Modernas. E-mail: cleci.bevilacqua@gmail.com

" Universidade Federal do Rio Grande do Sul (UFRGS). Instituto de Letras. Departamento de Línguas Modernas. E-mail: arcosmanuela@gmail.com
} 
Resumo: Este trabalho trata da Fraseologia Especializada relativa à Conservação e Restauração de Bens Culturais Móveis em papel. Seus objetivos foram: a identificação e extração de Unidades Fraseológicas Especializadas Eventivas (UFE eventivas), em língua portuguesa, e sua inserção na árvore de domínio da área da Conservação e Restauração. As UFE eventivas se constituem por um Núcleo Eventivo (NE) de natureza verbal e um Núcleo Terminológico (NT) de natureza nominal e indicam ações e processos especializados. As unidades analisadas foram extraídas do Corpus Papel (Termisul) utilizando a ferramenta Word Sketch do programa Sketch Engine. A partir da análise dos dados no corpus de estudo, apresentamos dois principais resultados: a observação do fenômeno da restrição combinatória que, nas UFE eventivas, parece incidir sobre o NE, e a observação do princípio da multidimensionalidade do NE.

Palavras-chave: Restrição combinatória; Multidimensionalidade; Unidades Fraseológicas Especializadas Eventivas; Conservação e Restauração de Bens Culturais Móveis em Papel.

Abstract: The current study deals with the Specialized Phraseology that concerns the Conservation and Restoration of Movable Goods on paper. The study aimed for: the identification and extraction of Eventive Specialized Phraseological Units (Eventive SPU), in Portuguese, and its insertion in the domain tree of the Conservation and Restoration field. The Eventive SPUs are made up of an Eventive Nucleus (EN) of verbal nature and a Terminological Nucleus (TN) of nominal nature; they indicate specialized actions and processes. The analyzed units were extracted from the Corpus Papel (Termisul) with the Word Sketch tool (of the Sketch Engine Program). From the analysis of the data in the corpus of study, we presented two main results: the observation of the selectional restriction phenomenon that, in the Eventive SPUs, seems to fall upon the EN; and the observation of the principle of the multidimensionality of the EN.

Keywords: Selectional Restriction; Multidimensionality; Eventive Specialized Phraseological Units; Conservation and Restoration of mobile cultural assets on paper.

TradTerm, São Paulo, v.37, n. 1, janeiro/2021, p. 294-329

Número Especial - Linguística de Corpus

www.revistas.usp.br/tradterm 


\section{Introdução}

Este trabalho apresenta os principais resultados qualitativos $\mathrm{da}$ pesquisa de Mestrado desenvolvida junto ao Programa de Pós-Graduação em Letras da UFRGS, na linha de pesquisa Lexicografia, Terminologia e Tradução: relações textuais ${ }^{1}$. A pesquisa se inseriu no projeto desenvolvido pelo Grupo Termisul (UFRGS) intitulado A Linguagem do Patrimônio Cultural Brasileiro: Conservação dos bens culturais móveis (2016-2019), cujo objetivo foi descrever as práticas textuais da área da Conservação e Restauração de bens em suporte papel a fim de reconhecer e explicitar sua organização conceitual e terminológica em uma base de dados terminológica on-line e multilíngue (português, espanhol, francês, inglês, italiano e russo), voltada para tradutores, revisores técnicos e estudantes da área.

0 propósito da pesquisa de Mestrado foi desenvolver uma das facetas do referido projeto a partir da identificação e da análise das Unidades Fraseológicas Especializadas eventivas (UFE eventivas, BEVILACQUA 2004) da área para compor a base de dados terminológica compilada pelo grupo. Para tanto, a pesquisa teve dois grandes objetivos: a) identificar e extrair as UFE eventivas, em língua portuguesa, da área da Conservação e Restauração de bens culturais móveis em suporte papel a serem inseridas na base de dados terminológica do Termisul; e b) analisar quantitativa e qualitativamente as UFE eventivas identificadas para incluí-las na árvore de domínio de Bojanoski $(2018)^{2}$ da referida área, complementando o desenho da estrutura conceitual da área.

Neste artigo, pretendemos discutir mais detidamente os resultados qualitativos, especificamente aqueles que dizem respeito ao fenômeno da restrição combinatória entre o núcleo eventivo (NE) e o núcleo terminológico (NT) e a relação desse fenômeno com o caráter multidimensional do NE,

\footnotetext{
${ }^{1}$ Este trabalho apresenta os resultados da pesquisa de mestrado realizada junto ao Programa de Pós-Graduação em Letras da UFRGS, defendida em 2019. Disponível em: https://lume.ufrgs.br/handle/10183/202482. A pesquisa foi realizada com apoio da Coordenação de Aperfeiçoamento de Pessoal de Nível Superior - Brasil (CAPES) - Código de Financiamento 001.

2 A árvore de domínio completa da área da Conservação e Restauração elaborada por Bojanoski encontra-se em sua tese de doutoramento, disponível em https://wp.ufpel.edu.br/ppgmp/files/2018/04/tese_Silvana_F_Bojanoski.pdf (2018: 286).
}

TradTerm, São Paulo, v.37, n. 1, janeiro/2021, p. 294-329

Número Especial - Linguística de Corpus

www.revistas.usp.br/tradterm 
conforme observamos a partir dos dados identificados. Paralelamente, com os procedimentos metodológicos adotados, buscamos ressaltar a importância da Linguística de Corpus para a identificação e análise dos termos coletados, bem como de seu funcionamento no âmbito estudado.

\section{Enfoque teórico}

Situamos nosso estudo sob o enfoque da Teoria Comunicativa da Terminologia (TCT) (CABRÉ 1999; 2002), que concebe a linguagem especializada não em oposição à língua geral, mas como uma manifestação da mesma em contextos específicos de comunicação. Essa teoria se fundamenta em princípios e condições (CABRÉ 1999), entre os quais destacamos, neste trabalho, o princípio da "poliedricidade" e da "multidimensionalidade" do termo.

O princípio da poliedricidade do termo se refere ao caráter inerentemente poliédrico das unidades terminológicas, que integram, concomitantemente, aspectos linguísticos, cognitivos e sociais. Nessa perspectiva, o termo é definido como uma unidade léxica poliédrica que, utilizada em certas condições discursivas, adquire um valor especializado e, portanto, é ao mesmo tempo igual e diferente das unidades léxicas de uma língua - palavras na lexicologia.

Quanto ao princípio da multidimensionalidade, Cabré (1999) assume que nenhuma matéria de estudo é capaz de abordar seu objeto de maneira global, mas apenas parcialmente. Essa parcialidade se deve não somente ao caráter poliédrico, mas também multidimensional de todo objeto - termo cuja abordagem sempre partirá de suas facetas diversas. A autora afirma que

Todo objeto pode fazer parte, e de fato faz parte, de diferentes campos de estudo (condição de poliedricidade), e em cada um deles se prioriza uma ou outra faceta. Ademais, cada objeto pode ser percebido dentro de uma disciplina a partir de diferentes pontos de vista (multidimensionalidade). (CABRÉ 1999: 94-95, tradução nossa) ${ }^{3}$.

\footnotetext{
${ }^{3}$ No original: Todo objeto puede formar parte, y de hecho forma parte, de diferentes campos de estudio (condición de poliedricidad) en cada uno de ellos se prioriza una u otra faceta, y

TradTerm, São Paulo, v.37, n. 1, janeiro/2021, p. 294-329 Número Especial - Linguística de Corpus www.revistas.usp.br/tradterm
} 
Cabré também se refere ao conceito de poliedricidade como sinônimo da "complexidade conceitual" do termo (1999: 97) e estabelece que o termo, justamente por sua natureza poliédrica, pode ser explicado em conexão com outras unidades concomitantes, que devem se localizar em uma teoria interdisciplinar que permita abordá-las parcialmente, sem pressupor que se está cobrindo completamente sua descrição.

A autora (1999) destaca ainda aspectos linguísticos - sintáticosemânticos - das unidades terminológicas, uma vez que os termos, bem como as unidades lexicais de um código estabelecido, são sistemáticos tanto na sua forma quanto no seu conteúdo, pois sua estrutura morfológica e sintática respeita as leis de formação de palavras e as regras de flexão de cada língua. Sob o ponto de vista semântico, os termos mantêm relações de significado com os demais termos que formam parte de um sistema conceitual de um âmbito especializado. Já no nível sintático, os termos são unidades distribucionais que se combinam com outros termos e outras palavras para formar sintagmas ${ }^{4}$ e orações, que, por sua vez, se combinam para formar textos.

Como já mencionado, as unidades sintagmáticas estudadas neste trabalho correspondem à proposta das Unidades Fraseológicas Especializadas Eventivas (UFE eventivas) de Bevilacqua (2004). A autora as define como unidades formadas por um ou mais termos que constituem seu núcleo terminológico (NT) e por um núcleo eventivo (NE), de caráter terminológico ou não, procedente de um verbo e que se manifesta como verbo, nome deverbal ou particípio (BEVILACQUA 2004: 16).

O NT representa um nó de conhecimento na estrutura ou mapa conceitual da área de especialidade. É de categoria nominal, apresenta um valor referencial e possui caráter denominativo/conceitual, podendo aparecer na forma de um termo simples ou sintagmático. Por sua vez, o NE é de categoria verbal ou derivada de verbo - como nominalizações e particípios -,

además cada objeto puede ser percibido dentro de una disciplina desde puntos de vista distintos (multidimensionalidad).

${ }^{4}$ Destacamos que, ao fazer referência à formação de sintagmas, a autora abre espaço para a fraseologia especializada, posto que alguns desses tipos de unidades, como as que trataremos no presente trabalho, conformam sintagmas.

TradTerm, São Paulo, v.37, n. 1, janeiro/2021, p. 294-329

Número Especial - Linguística de Corpus

www.revistas.usp.br/tradterm 
tem um caráter relacional, e denota processos e ações próprias de um âmbito do conhecimento (BEVILACQUA 2004: 17).

Entre o NE e o NT se estabelecem relações sintáticas e semânticas determinadas por seu uso no âmbito temático - o que confere às UFE eventivas um caráter de estabilidade ou semifixação - e uma frequência relevante nos textos especializados. Portanto, são unidades que se formam e que adquirem valor especializado no contexto de uso de uma área do conhecimento.

A autora (2004: 18) apresenta três possíveis estruturas de UFE eventivas, sendo todas formadas por um ou mais termos - que constituem seu núcleo terminológico (NT) - e por um núcleo eventivo (NE), de caráter terminológico ou não, que pode se manifestar como verbo, nome deverbal ou particípio:

$$
\begin{array}{ll}
{[N E]_{V}+[N T]_{N}} & \text { consumir energia } \\
{[N E]_{N d e v}+[N T]_{S P}} & \text { consumo de energia } \\
{[N T]_{N}+[N E]_{\text {PartAdj }}{ }^{5}} & \text { energia consumida } 6
\end{array}
$$

Para analisar as relações conceituais que se estabelecem entre NT e NE das UFE eventivas, seguimos a proposta de Sager (1990). Segundo o autor, entre as tarefas do trabalho terminológico está o estabelecimento de um vínculo entre conceitos e termos por meio das definições. A construção de definições, por sua vez, cria e estabelece relações entre conceitos dentro da estrutura de conhecimento de um campo. Na medida em que se adicionam novos conceitos, amplia-se, também, a estrutura de conhecimento do âmbito. Para descrever como se constituem as estruturas conceituais dos diferentes campos de especialidade, Sager (1990: 50) apresenta os "tipos de conceitos" e os "tipos de relações" entre conceitos, conforme ilustra o Quadro 1.

Quadro 1 - Estruturas conceituais por Sager (1990)

\begin{tabular}{|l|l|}
\hline Tipos de conceitos & entidades \\
\cline { 2 - 2 } & atividades \\
\hline
\end{tabular}

\footnotetext{
${ }^{5} \mathrm{~V}=$ verbo; $\mathrm{N}=$ nome; $\mathrm{Ndev}=$ Nome deverbal; $\mathrm{SP}=$ sintagma preposicionado; PartAdj $=$ Particípio/Adjetivo.

${ }^{6}$ No original: consumir energía, consumo de energía, energía consumida.
}

TradTerm, São Paulo, v.37, n. 1, janeiro/2021, p. 294-329

Número Especial - Linguística de Corpus www.revistas.usp.br/tradterm 


\begin{tabular}{|l|l|}
\hline & qualidades \\
\hline Tipos de relações & genéricas \\
\cline { 2 - 2 } & polivalentes \\
\hline
\end{tabular}

Fonte: as autoras

As "entidades" derivam da abstração dos objetos materiais ou abstratos, e as “atividades" são os processos, operações e ações realizadas com, mediante ou por meio das entidades. Para o nosso trabalho de estruturação conceitual das UFE eventivas identificadas, entendemos as entidades como o NT e as atividades como o NE. Por exemplo, na UFE eventiva preservação de acervo, o NE preservação é a atividade, isto é, o processo que a entidade (NT acervo) sofre. As “qualidades" estabelecem diferenças entre as entidades. Por isso, poderíamos considerar as qualidades como elementos que se aplicam às entidades para distingui-las, como no caso dos termos sintagmáticos “papel mata-borrão" e "papel japonês”, em que “mata-borrão” e “japonês” seriam as qualidades que estabelecem diferenças entre a entidade (NT) "papel”.

Já as "relações" são aplicadas para estabelecer ligações entre as entidades e as atividades. Por exemplo, na organização conceitual da área da Conservação e Restauração, podemos dizer que a UFE Eventiva “laminação de documento" estabelece uma relação conceitual com a UFE Eventiva “restauração de documento", posto que a "laminação" é um processo que faz parte do processo de restauração. Desse modo, os tipos de conceitos podem ser apresentados dentro de uma estrutura sistemática, na qual devem ser caracterizados mediante as relações que estabelecem com outros conceitos.

Destacamos um tipo específico de relação conceitual apresentada por Sager: as "relações polivalentes". Neste tipo de relação, leva-se em conta a posição de um conceito dentro de um sistema conceitual, para o qual é preciso avaliar suas diferentes atribuições. Para isso, é necessário levar em conta, também, todas as relações de um conceito com outros conceitos. 0 autor (1990: 61) oferece como exemplo o termo “laminação”, que pode estar posicionado em diferentes lugares numa mesma estrutura conceitual:

TradTerm, São Paulo, v.37, n. 1, janeiro/2021, p. 294-329 Número Especial - Linguística de Corpus www.revistas.usp.br/tradterm 
"Laminação":

- parte de um processo de encadernação;

- parte de um processo de conservação de livros.

Portanto, as relações polivalentes constituem "relações polihierárquicas", isto é, quando um conceito se posiciona em mais de uma hierarquia dentro de um campo temático específico. Associamos as relações polivalentes com o conceito de multidimensionalidade proposto por Cabré (1999), que se refere, como já mencionado, à possibilidade de que um mesmo objeto possa ser percebido a partir de diferentes pontos de vista dentro de uma mesma disciplina. Nos nossos dados, identificamos alguns NE que se localizam na árvore de domínio de maneira poli-hierárquica e multidimensional, pois assumem diferentes valores no âmbito da Conservação e Restauração. Com isso, um mesmo NE poderá aparecer em diferentes núcleos conceituais da árvore de domínio de um âmbito de conhecimento por se referir a diferentes processos na estrutura conceitual da área.

Após apresentar a síntese da fundamentação teórica que sustenta o trabalho, apresentamos o corpus de estudo utilizado e os procedimentos para a identificação das UFE eventivas.

\section{Metodologia}

Para identificar as UFE eventivas, utilizamos o Corpus ${ }^{7}$ Papel, construído pelo grupo Termisul segundo os seguintes critérios:

a) aplicação de filtros relacionados aos gêneros textuais (artigos, relatórios, anais, livros etc.);

b) busca a partir de palavras-chaves da área: "conservação", "restauração", "documentos" etc.;

c) busca em sites confiáveis (universidades, órgãos e entidades públicas e privadas).

\footnotetext{
${ }^{7}$ A partir de autores como Sánchez (1995) e Berber Sardinha (2000), entendemos o corpus como um conjunto de dados linguísticos, escritos e orais, coletados e sistematizados a partir de critérios, que constituem amostras representativas do uso da linguagem e que estão organizados de forma a serem processados por ferramentas informáticas.
}

TradTerm, São Paulo, v.37, n. 1, janeiro/2021, p. 294-329

Número Especial - Linguística de Corpus www.revistas.usp.br/tradterm 
Os textos coletados foram convertidos para o formato <.txt $>$, limpos (exclusão de sumário, figuras, referências), codificados e catalogados. Para exemplificar a codificação trazemos o exemplo: ptPP105 - HOLLOS, Adriana Cox. Fundamentos da Preservação Documental no Brasil. Revista Acervo, Rio de Janeiro, V. 23, n. 2, jul-dez, 2010 -, em que pt refere-se à língua portuguesa e PP a Projeto Papel, seguidos do número do texto (105). 0 número total de tokens do corpus é de cerca de 1 milhão, com um total de 161 textos.

Para identificar e extrair as UFE eventivas do Corpus Papel, utilizamos a ferramenta Word Sketch, do programa Sketch Engine $(\mathrm{SE})^{8}$, que permite a identificação de padrões colocacionais. Para tanto, nossa busca iniciou-se pelo NT e, a partir dele, identificamos os NE. Nossos critérios de seleção foram: mínimo de 5 ocorrências com distribuição em dois ou mais textos. A figura 1 ilustra o resultado da pesquisa com a palavra de busca acervo.

Figura 1 - Word Sketch do NT "acervo"

acervo (noun)

\begin{tabular}{|c|c|c|c|c|c|}
\hline \multicolumn{2}{|l|}{1 ...de acervo } & \multirow{2}{*}{$\begin{array}{r}53.85 \\
11.53\end{array}$} & \multicolumn{2}{|c|}{2 V objacervo $\mathrm{N}$} & \multirow{2}{*}{$\begin{array}{r}7.56 \\
11.12\end{array}$} \\
\hline $\begin{array}{l}\text { preservação + } \\
\quad \text { preservação de acervos }\end{array}$ & $\underline{279}$ & & \multicolumn{2}{|c|}{$\begin{array}{l}\text { compor } \quad \underline{\underline{29}} \\
\text { que compõem o acervo }\end{array}$} & \\
\hline $\begin{array}{l}\text { conservaçãa + } \\
\text { conservação do acervo }\end{array}$ & $\underline{185}$ & 11.04 & $\begin{array}{l}\text { abrigar } \\
\text { que ab }\end{array}$ & $\begin{aligned} \underline{20} \\
\text { rvos }\end{aligned}$ & 10.75 \\
\hline $\begin{array}{l}\text { guarda } \\
\text { de guarda de acervos }\end{array}$ & $\underline{72}$ & 10.00 & $\begin{array}{r}\text { preservar } \\
\text { presen }\end{array}$ & $\underline{16}$ & 10.16 \\
\hline $\begin{array}{l}\text { parte } \\
\text { parte do acervo }\end{array}$ & $\underline{49}$ & 9.17 & $\begin{array}{l}\text { possuir } \\
\text { manter }\end{array}$ & $\frac{13}{10}$ & $\begin{array}{l}9.04 \\
9.23\end{array}$ \\
\hline $\begin{array}{l}\text { restauração } \\
\quad \text { conservação e restauração }\end{array}$ & $\begin{array}{l}\underline{43} \\
\text { acervo }\end{array}$ & 8.94 & $\begin{array}{l}\text { constituir } \\
\text { proteger }\end{array}$ & $\begin{array}{l}\underline{9} \\
\underline{8}\end{array}$ & $\begin{array}{l}9.28 \\
9.37\end{array}$ \\
\hline higienização & $\underline{42}$ & 9.28 & afetam & $\underline{7}$ & 9.39 \\
\hline a higienização do acervo & & & integrar & $\underline{7}$ & 9.35 \\
\hline unidade & $\underline{40}$ & 9.22 & atacar & $\underline{7}$ & 9.22 \\
\hline unidade do acervo & & & danificar & $\underline{6}$ & 9.09 \\
\hline deterioração & $\underline{38}$ & 9.09 & divulgar & $\underline{5}$ & 8.97 \\
\hline deterioração dos acervos & & & guardar & $\underline{5}$ & 8.91 \\
\hline tratamento & $\underline{34}$ & 8.80 & conservar & $\underline{5}$ & 8.86 \\
\hline tratamento do acervo & & & envolver & $\underline{5}$ & 8.52 \\
\hline
\end{tabular}

Fonte: adaptado de https://www.sketchengine.co.uk/

Uma vez feito o Word Sketch, analisamos individualmente cada candidato a UFE eventiva a fim de confirmar se se tratava de processos especializados do âmbito. Com essa metodologia, identificamos 318 UFE

\footnotetext{
${ }^{8}$ http://www.sketchengine.eu.

TradTerm, São Paulo, v.37, n. 1, janeiro/2021, p. 294-329

Número Especial - Linguística de Corpus

www.revistas.usp.br/tradterm
} 
eventivas a partir de $65 \mathrm{NT}^{9}$ da área da Conservação e Restauração. Desse total, 245 unidades eram de padrão morfossintático [NE] Ndev $+[\mathrm{NT}] \mathrm{sP}$, e 73 de padrão $[\mathrm{NE}] \mathrm{v}+[\mathrm{NT}] \mathrm{N}^{10}$.

Para analisar qualitativamente os dados, selecionamos os 5 NT mais produtivos fraseologicamente, isto é, aqueles que mais formaram UFE eventivas: “acervo”, “documento", “livro”, “obra” e “papel”. Esses 5 NT produziram um total de 191 unidades, conforme ilustra a tabela 1.

Tabela 1 - Produtividade dos 5 NT analisados qualitativamente

\begin{tabular}{|l|c|}
\hline \multicolumn{1}{|c|}{ NT } & $\mathbf{N}^{\circ}$ de UFE eventivas \\
\hline acervo & 54 \\
\hline documento & 61 \\
\hline livro & 29 \\
\hline obra & 20 \\
\hline papel & 27 \\
\hline Total & 191 \\
\hline
\end{tabular}

Fonte: as autoras

Ressaltamos que os resultados qualitativos apresentados e discutidos neste artigo fazem parte desse recorte de dados. Portanto, a fim de situar a discussão sobre a restrição combinatória e a multidimensionalidade, apresentamos brevemente a metodologia que seguimos para analisar qualitativamente essas 191 unidades.

A análise qualitativa do nosso trabalho ganhou importância no momento em que começamos a organizar as 191 UFE eventivas identificadas para inserilas na árvore de domínio de Bojanoski (2018). Para essa tarefa, a análise detalhada dos contextos de uso das unidades foi fundamental, pois foi a partir dela que observamos alguns funcionamentos padrão das UFE eventivas analisadas.

\footnotetext{
${ }^{9}$ Os NTs correspondem a termos identificados pelo grupo utilizando a ferramenta Keyword do mesmo programa. 0 corte de frequência aplicado foi 10 e os termos deveriam poder ser inseridos na árvore de Bojanoski (2018). Alguns exemplos: arquivo, bens, fibra, livro, sujidade.

${ }^{10}$ As UFE eventivas de padrão morfossintático $[N T]_{N}+[N E]_{\text {partadj }}$ não foram consideradas na pesquisa, posto que não seriam inseridas na base de dados terminológica elaborada pelo grupo Termisul.
}

TradTerm, São Paulo, v.37, n. 1, janeiro/2021, p. 294-329

Número Especial - Linguística de Corpus www.revistas.usp.br/tradterm 
Assim, foi possível identificar seus sentidos e, logo, localizar seus NE (processos) na árvore de domínio. Por exemplo, para determinar o valor dos processos “reprodução” e “digitalização de acervo” e situá-los na árvore de domínio, buscamos inicialmente, no corpus, um contexto que definisse esses processos. Para isso, usamos a ferramenta concordanciador do SE, que recupera, na mesma tela, todas as concordâncias do NE pesquisado, conforme ilustra a figura 2 .

Figura 2 - Concordâncias da UFE Eventiva reprodução de acervo (SE).

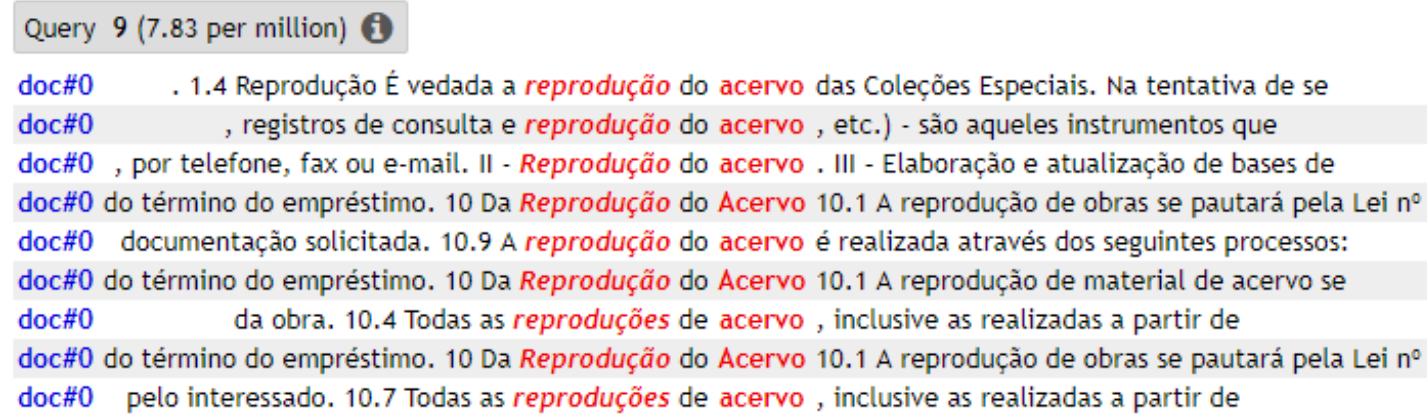

Fonte: Sketch Engine

A partir da leitura de cada um dos contextos, identificamos um contexto definitório do processo de reprodução. Ao identificar esse contexto, copiamos os fragmentos para um arquivo .doc, a fim de organizar os sentidos identificados para cada processo, conforme ilustra a figura 3.

Figura 3 - Arquivo .doc com os contextos de uso dos processos identificados.

\section{REPRODUÇÃO DE ACERVO}

$\leq$ previous qual se compromete em indicar o crédito da Fundaj como instituição detentora dos documentos reproduzidos, conforme indicado no item 9.14 deste manual e, principalmente, informar a finalidade do uso da documentação solicitada. 10.9 A reprodução do acervo é realizada através dos seguintes processos: digitalização, copiagem, microfilmagem e fotocópia. 10.10 Reproduções realizadas a partir de empréstimos autorizados pelo Cehibra devem seguir as normas descritas nos itens 9.13, 9.14, 9.15 e 9.16 deste documento, na parte que se refere ao Centro de Documentação e de Estudos da História Brasileira. 10.11 No caso de reproduções para fins publicitários, com fins comerciais, será cobrada uma taxa de manutenção do acervo, no valor referente a 3\% do valor do documento, estipulado para seguro. 11 Da Responsabilidade do Usuário next >

Fonte: as autoras

No contexto de uso selecionado, observamos que reprodução de acervo é um processo que engloba a “digitalização", a “copiagem”, a “microfilmagem" e a "fotocópia”. Portanto, a partir dessa relação conceitual,

TradTerm, São Paulo, v.37, n. 1, janeiro/2021, p. 294-329 Número Especial - Linguística de Corpus www.revistas.usp.br/tradterm 
inserimos na árvore de domínio o processo de "digitalização de acervo" como uma forma de sua "reprodução", isto é, subordinamos o processo de "digitalização" ao de "reprodução de acervo".

Uma vez que esses processos não estavam presentes na árvore de domínio de Bojanoski (2018), propusemos sua inserção em "1 Identificar > 1.3 História e caracterização das técnicas e materiais > 1.3.3 Meios de reprodução da informação > digitalização", como um complemento a "1.3.2 Meios de registro da informação", conforme ilustra a figura $4^{11}$.

Figura 4 - Proposta de inserção dos processos "reprodução" e "digitalização de acervo" na árvore de domínio de Bojanoski $\left(2018^{12}\right)$.

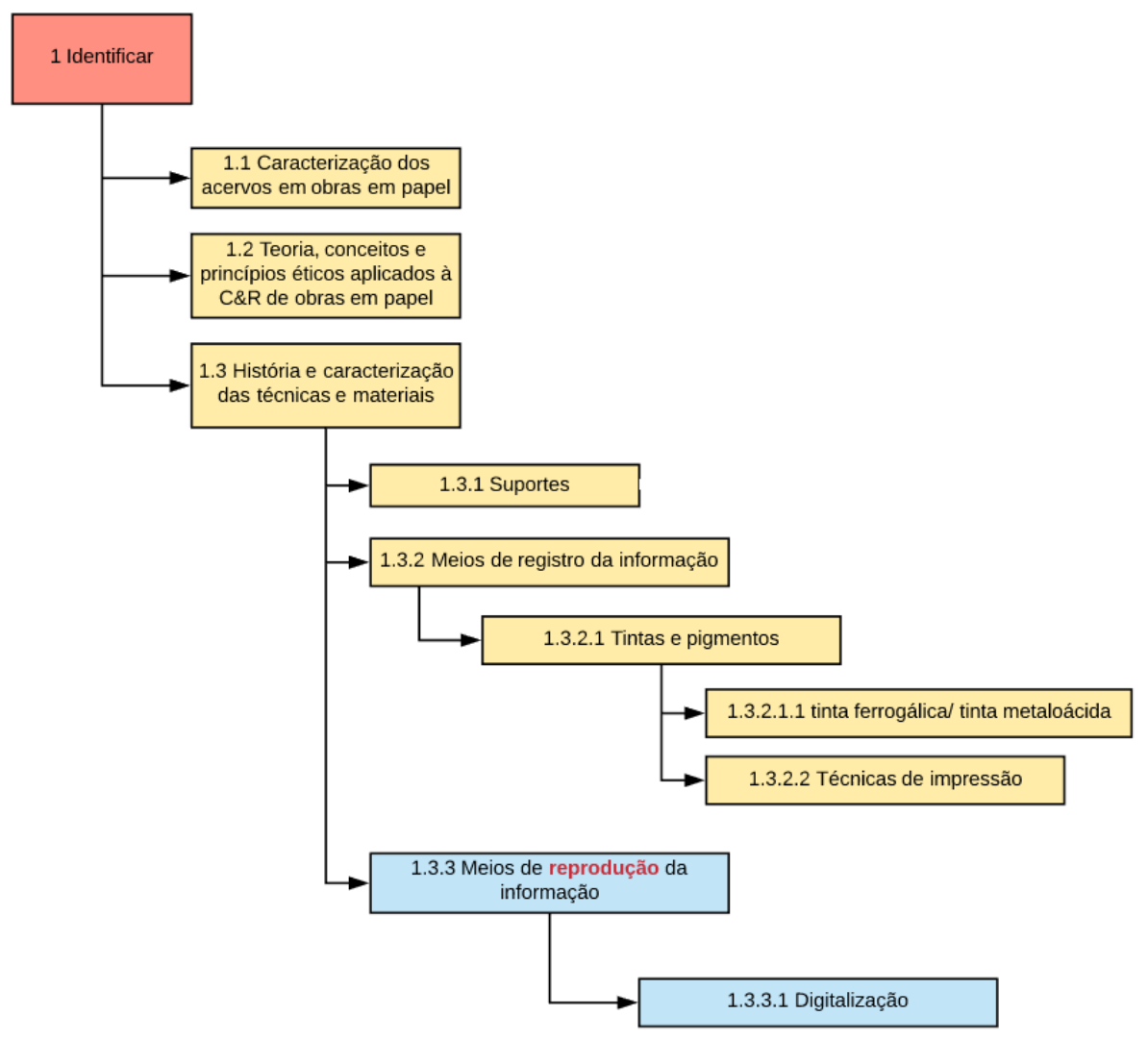

Fonte: $\operatorname{Arcos}(2019: 90)$

11 Optamos por usar três cores como legenda a fim de marcar os dados extraídos: em vermelho estão os núcleos conceituais que identificamos no Corpus Papel e que já estavam inseridas na árvore de Bojanoski (2018); em amarelo estão os núcleos propostos pela autora, que não identificamos no Corpus Papel, e, em azul, estão os núcleos conceituais que identificamos no Corpus Papel, mas que não estavam presentes na árvore da autora.

12 Todos os hiperônimos que ordenam conceitualmente a árvore de domínio - tanto os de Bojanoski (2018) quanto os de nosso estudo, como 1 Identificar e 6 Administração - foram inseridos na árvore seguindo um critério de frequência de aparição no corpus de estudo.

TradTerm, São Paulo, v.37, n. 1, janeiro/2021, p. 294-329

Número Especial - Linguística de Corpus 
O núcleo conceitual "meios de reprodução da informação (1.3.3)" é uma proposta nossa de inserção na árvore, pois explicita o processo de "reprodução de acervos" que identificamos no corpus e que não estavam presentes na árvore de domínio de Bojanoski (2018). Portanto, foram identificados processos que não faziam parte da estrutura conceitual da árvore de domínio da autora, embora também fossem identificados processos que já estavam registrados.

Durante a realização da análise qualitativa das 191 UFE eventivas para a sua inserção na árvore de domínio ${ }^{13}$, conforme ilustramos anteriormente, observamos alguns padrões de comportamento do NE (processos), dos quais destacamos neste trabalho: os casos de "NE específicos" (de alta restrição combinatória) e os casos de "NE multidimensionais". Nas seções seguintes, comentamos ambos os casos a fim de ilustrar os resultados aos quais chegamos.

\section{O fenômeno da restrição combinatória observado a partir do comportamento do NE}

A restrição combinatória é uma característica das unidades fraseológicas, sendo descrita por diferentes autores e sob diferentes perspectivas. L'Homme e Bertrand (2000) caracterizam as unidades sintagmáticas de especialidade como combinações que resultam do consenso de uso entre os especialistas de um âmbito, o que gera uma imprevisibilidade em sua constituição. Para Bevilacqua (2004: 16), entre o NT e o NE se estabelecem relações sintáticas e semânticas determinadas por condições pragmático-discursivas que conferem às UFE eventivas um caráter estável de semifixação.

Outros autores se referem ao fenômeno da restrição combinatória, como Hausmann (1990), que destaca a existência de uma restrição semântica

${ }^{13} \mathrm{Em}$ função do grande número de processos que identificamos a partir dos $5 \mathrm{NT}$ (acervo, documento, livro, obra e papel) e dos diferentes processos com os quais cada NT se combina, optamos por adaptar individualmente a árvore de Bojanoski para cada um dos 5 NT. Portanto, como resultado final da nossa pesquisa, produzimos cinco árvores de domínio adaptadas.

TradTerm, São Paulo, v.37, n. 1, janeiro/2021, p. 294-329

Número Especial - Linguística de Corpus

www.revistas.usp.br/tradterm 
entre dois elementos que se combinam - o que aumenta seu grau de lexicalização. Béjoint e Thoiron (1992) falam de uma associação privilegiada entre quaisquer palavras ou termos conectados por uma estrutura sintática na qual as afinidades sintagmáticas se concretizam por certa recorrência no discurso. Da mesma forma, Blais (1993) ressalta que, em uma combinação de elementos linguísticos próprios de um domínio de especialidade, os elementos se ligam sintática e semanticamente por uma restrição paradigmática.

Por sua vez, Kjaer (1990) destaca que as unidades fraseológicas podem apresentar desde um grau de fixação e previsibilidade menor até um alto grau de idiossincrasia (1990: 19). Segundo a autora, estas unidades merecem maior interesse no estudo da fraseologia especializada, uma vez que faltam razões que expliquem e justifiquem de maneira satisfatória suas restrições combinatórias.

Dado que assumimos o fenômeno da restrição combinatória como constituinte de toda UFE eventiva, identificamos dois padrões de resultados na análise qualitativa: unidades com menor restrição combinatória e unidades com maior restrição combinatória. A seguir, pretendemos demonstrar que, pela análise dos dados identificados ao longo da pesquisa, o fenômeno da restrição combinatória que se estabelece entre o NT e o NE parece incidir mais sobre o NE.

Durante a análise dos dados e da combinação entre NT e NE, identificamos dois padrões de combinação:

a) NE com valores mais amplos - hiperônimos - que se combinam com diversos NT, e

b) NE com valores mais específicos, que apresentam maior restrição para se combinarem com diferentes NT.

Por exemplo, entre os NE hiperônimos, observamos processos como “tratamento”, “conservação” e "restauração”, que são NE que se combinam com os 5 NT no corpus, formando UFE eventivas como "tratamento de acervo", "tratamento de documento", "tratamento de livro", "tratamento de obra”, “tratamento de papel”, “conservação de acervo”, "conservação de documento”, “conservação de livro”, “conservação de obra”, “conservação de papel” e "restauração de acervo”, “restauração de documento”, “restauração

TradTerm, São Paulo, v.37, n. 1, janeiro/2021, p. 294-329 Número Especial - Linguística de Corpus www.revistas.usp.br/tradterm 
de livro", "restauração de obra", "restauração de papel”. Nossa conclusão de que tais $\mathrm{NE}$ se referiam a processos mais amplos se deve ao fato de que, nas concordâncias, os valores desses NE se referiam a diferentes processos dentro do sistema conceitual da área, funcionando, de fato, como hiperônimos. Assim, tratamento de acervo ora faz referência a um processo amplo de Conservação e Restauração, ora funciona como um sinônimo de um processo mais específico, como, por exemplo, a "limpeza" ou o "manuseio" do acervo.

Por outro lado, cada um dos 5 NT (acervo, documento, livro, obra e papel) também se combinam de maneira exclusiva com certos NE, em UFE eventivas como "costura de livro", "encadernação de livro" e "montagem de livro", "desmonte de obra" e "planificação de obra", ou, ainda, "amarelecimento de papel", "colagem de papel”, "planificação de papel" e "envelhecimento de papel", entre outros. Desse modo, identificamos que esses NE que parecem se combinar de forma exclusiva com os NT se referiam a processos mais específicos da área da Conservação e Restauração, isto é, NE cujos processos são mais delimitados conceitualmente dentro da área.

Num primeiro momento, acreditávamos que essa maior restrição combinatória pudesse estar atrelada ao fato de que "acervo", "documento", "livro" e "obra" se aproximam mais ao suporte "papel" - objeto central do corpus -, de modo que os processos relativos a esses NT poderiam também estar mais próximos à área da Conservação e Restauração. No entanto, partindo do princípio da poliedricidade da TCT, os NT podem fazer parte de outras estruturas conceituais de diversas áreas do conhecimento, e, portanto, podem se combinar com diferentes processos de diferentes áreas.

Por isso, entendemos que a restrição combinatória entre NT e NE poderia incidir mais sobre o NE. Para testar nossa hipótese, invertemos a busca no corpus utilizando a ferramenta Word Sketch. Isto é, realizamos a busca partindo dos NE que se combinam exclusivamente com os 5 NT. A partir dessa busca invertida, observamos que, de fato, tais NE não combinam com outros NT dentro do corpus.

TradTerm, São Paulo, v.37, n. 1, janeiro/2021, p. 294-329 Número Especial - Linguística de Corpus www.revistas.usp.br/tradterm 
Por exemplo, ao pesquisarmos no corpus os NE exclusivos de cada um dos 5 NT seguidos da preposição de ("fabricação + de", "amarelecimento + de", “colagem + de", "escurecimento + de", “tingimento + de"), constatamos que esses NE se combinam apenas com o NT "papel" no corpus ou com outros termos que fazem menção a papel. A Figura 5 ilustra esses resultados.

Figura 5 - Busca no corpus a partir dos NE exclusivos do NT "papel”

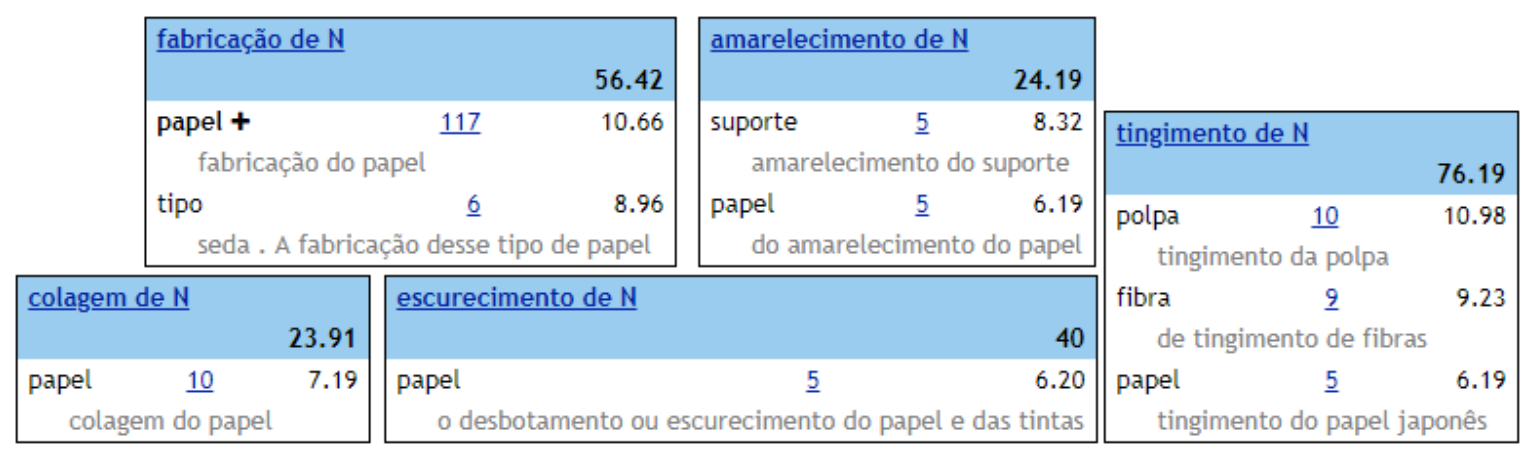

Fonte: $\operatorname{Arcos}(2019: 128)$

No caso do NE "amarelecimento", observamos que ele também se combina com o NT "suporte", e que o NE "tingimento" se combina com os NT “polpa” e “fibra”. No entanto, esses NT fazem menção ao NT “papel”. Isto é, "suporte" se refere ao "suporte papel”, “polpa” se refere à "polpa de celulose", usada na fabricação de papel, e "fibra" se refere à "fibra do papel". Resultados semelhantes observamos para os demais NT livro e obra, e inclusive para os NT acervo e documento, conforme ilustram as figuras $6,7,8$ e 9.

TradTerm, São Paulo, v.37, n. 1, janeiro/2021, p. 294-329

Número Especial - Linguística de Corpus

www.revistas.usp.br/tradterm 
Figura 6 - Busca no corpus a partir dos NE exclusivos do NT "livro”.

\begin{tabular}{|c|c|c|}
\hline \multicolumn{2}{|l|}{ encadernação de $\mathrm{N}$} & 16.09 \\
\hline \multicolumn{2}{|c|}{$\begin{array}{l}\text { luxo } \\
\qquad \text { para as encadernações de luxo }\end{array}$} & 11.97 \\
\hline \multicolumn{2}{|c|}{$\begin{array}{l}\text { ourivesaria } \\
\qquad \text { a encadernação de ourivesaria }\end{array}$} & 10.30 \\
\hline \multicolumn{2}{|c|}{$\begin{array}{l}\text { couro } \\
\qquad \text { A encadernação de couro }\end{array}$} & 10.15 \\
\hline \multicolumn{2}{|c|}{$\begin{array}{l}\text { época } \\
\text { encadernação dessa época }\end{array}$} & 9.40 \\
\hline $\begin{array}{l}\text { século } \\
\text { encadernações do século }\end{array}$ & éculo & 9.13 \\
\hline tipo & $\underline{6}$ & 8.96 \\
\hline \multicolumn{3}{|c|}{ Encadernação original do tipo flexível } \\
\hline \multicolumn{2}{|c|}{$\begin{array}{l}\text { livro } \\
\quad \text { encadernações de livros }\end{array}$} & 8.41 \\
\hline \multicolumn{2}{|c|}{$\begin{array}{l}\text { conservação } \\
\text { encadernação de conservação }\end{array}$} & 7.92 \\
\hline \begin{tabular}{|l|l|} 
abertura de N & \\
& 46.43
\end{tabular} & publicação de N & 33.57 \\
\hline \multirow[t]{2}{*}{$\begin{array}{l}\text { livro } \quad \underline{6} \quad 7.42 \\
\text { abertura do livro }\end{array}$} & \multirow{2}{*}{$\begin{array}{l}\text { portaria } \\
\text { publicação de portaria } \\
\text { da Presidência } \\
\text { livro } \\
\text { publicação de livros }\end{array}$} & $\begin{array}{ll}\underline{6} & 10.88\end{array}$ \\
\hline & & $\underline{6} \quad 7.37$ \\
\hline
\end{tabular}

Fonte: $\operatorname{Arcos}$ (2019: 129)

No caso dos NE de “livro" (figura 6), por exemplo, o NE “encadernação” tem como objeto direto somente o NT “livro", uma vez que os demais coocorrentes são características da encadernação (de couro, de ourivesaria, isto é, não se encaderna nem o “couro" nem o “ouro”). No caso do NE publicação, identificamos publicação de portaria, que não é um NT da área da Conservação e Restauração.

O mesmo ocorre com os NE exclusivos do NT "obra” (figura 7), em que os NE “desmonte" e "planificação” se combinam somente com o NT “obra”. Já o NE "reconhecimento" se combina com os NT "valor" e "obra". No entanto, quando observamos os contextos (apresentados a seguir), o NE "reconhecimento" se refere ao reconhecimento da importância/relevância do material, enquanto o "reconhecimento de obra" se refere a um processo metodológico de restauração que consiste na avaliação da condição física, estética e histórica da obra. Portanto, poderíamos considerar que o NE 
"reconhecimento" se refere a processos diferentes em função dos NT com os quais se combina, conforme os contextos 1 e 2 identificados no Corpus Papel.

1. Este aceite define-se tanto pelo reconhecimento das características físicas inerentes à qualidade de produção dos documentos como pelo reconhecimento de seu valor perante a coleção, a instituição ou a coletividade. (Corpus Papel Termisul).

2. Para ele, "a restauração constitui o momento metodológico de reconhecimento da obra de arte, na sua condição física e na sua dupla polaridade estética e histórica e a sua transmissão para o futuro". (Corpus Papel Termisul).

Figura 7- Busca no corpus a partir dos NE exclusivos do NT "obra"

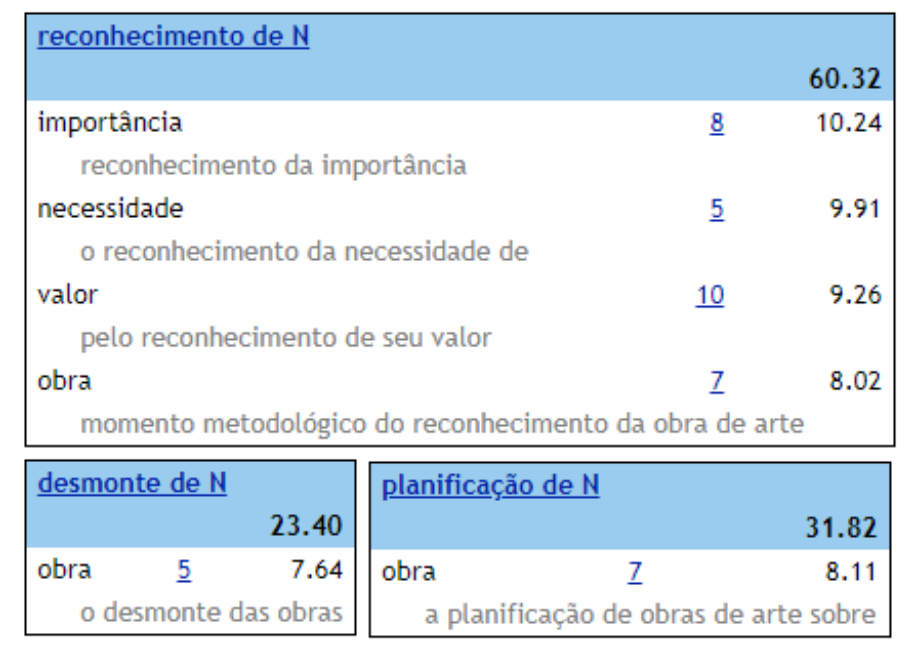

Fonte: $\operatorname{Arcos}(2019: 130)$

Os NE de "acervo" também se combinam restritamente. Observamos na Figura 8 que os NE “climatização”, “transferência”, “contaminação” e “biodeterioração" parecem ser processos que ocorrem somente com o NT “acervo". É interessante observar que mesmo em NE de áreas afins - como Biblioteconomia e Arquivologia - à Conservação e Restauração, como em divulgação de acervo, ocorre, também, a restrição combinatória. 
Figura 8 - Busca no corpus a partir dos NE exclusivos do NT "acervo"

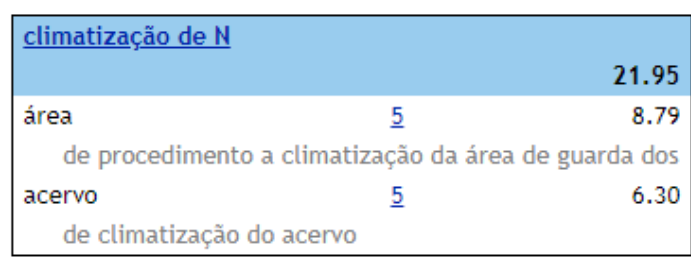

\begin{tabular}{|c|c|c|c|c|c|}
\hline \multirow{2}{*}{\multicolumn{3}{|c|}{$\begin{array}{ll}\text { divulgação de } \mathrm{N} & \\
51.11\end{array}$}} & \multirow{2}{*}{\multicolumn{3}{|c|}{60}} \\
\hline & & & & & \\
\hline acervo & & 7.12 & acervo & $\underline{\underline{ }}$ & 6.54 \\
\hline \multicolumn{3}{|c|}{ divulgação do acervo } & \multicolumn{3}{|c|}{ transferência do acervo } \\
\hline
\end{tabular}

\begin{tabular}{|lcr|}
\hline \multicolumn{2}{|c|}{ contaminação de $\mathrm{N}$} & 19.09 \\
acervo & $\underline{7}$ & 6.78 \\
O índice de contaminação do acervo & \\
\hline
\end{tabular}

\begin{tabular}{|lrr|}
\hline biodeterioração de $N$ & 21.05 \\
\hline acervo & $\underline{5}$ & 6.30 \\
da biodeterioração de acervos \\
\hline
\end{tabular}

Fonte: $\operatorname{Arcos}(2019: 130)$

Finalmente, o mesmo foi observado com o NT "documento" (figura 9), cujos NE também coocorrem restritamente, mesmo em alguns casos de NE de áreas afins, como “classificação" e “reunião" - que, pelo seu significado, estão mais relacionados à área da Biblioteconomia - e do âmbito da Conservação e Restauração, como “arquivamento” e “microfilmagem”.

Figura 9 - Busca no corpus a partir dos NE exclusivos do NT "documento"

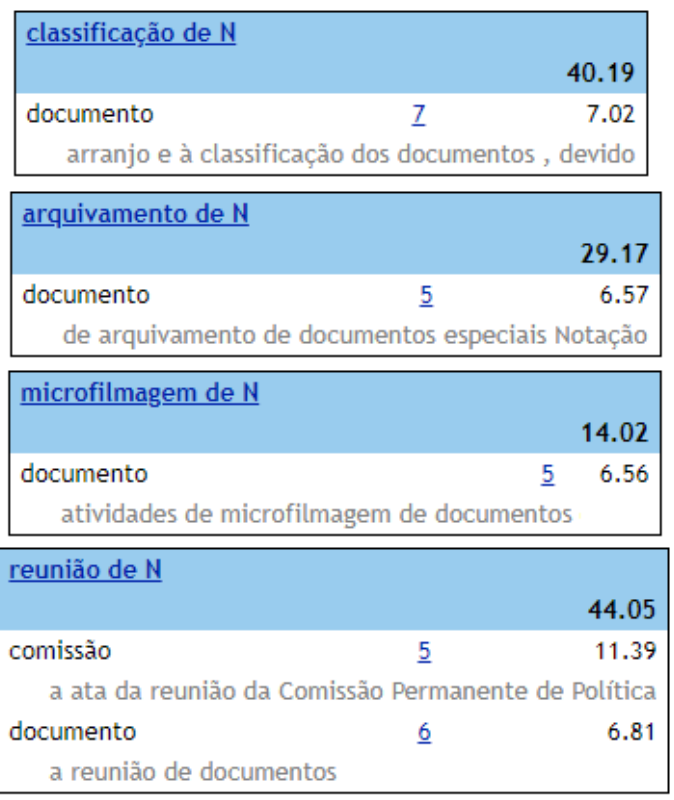

Fonte: $\operatorname{Arcos}(2019: 131)$

TradTerm, São Paulo, v.37, n. 1, janeiro/2021, p. 294-329

Número Especial - Linguística de Corpus

www.revistas.usp.br/tradterm 
Em síntese, com base na busca invertida, feita a partir do $\mathrm{NE}$, observamos que a restrição combinatória entre os dois núcleos (NE e NT) parece recair mais sobre o valor especializado do NE, sobretudo quando eles se referem a processos específicos da área de domínio (como "colagem de papel”, “abertura de livro", "planificação de obra”, "biodeterioração de acervo", "microfilmagem de documento"). Entretanto, mesmo alguns NE que poderiam ser encontrados também em outras áreas, como em "classificação" e "reunião de documento", ou, ainda, "divulgação de acervo", também se observa o fenômeno da restrição combinatória.

Por outro lado, também identificamos NE da área da Conservação e Restauração que apresentaram uma menor restrição em sua combinação, como, por exemplo, o NE "eliminação", que se combina com os NT "sujidade”, "fungo", “inseto" e "documento", conforme ilustra a figura 10.

Figura 10 - Busca no Word Sketch a partir do NE "eliminação"

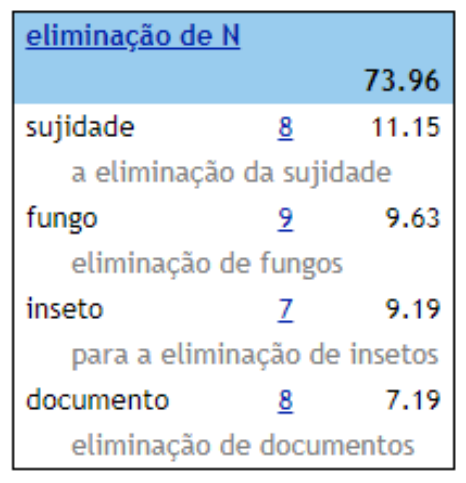

Fonte: $\operatorname{Arcos}(2019: 133)$

Nesse caso, observamos que o NE "eliminação" refere-se a diferentes processos dentro do sistema conceitual da área. Enquanto a "eliminação de sujidade" e de "fungos" trata da remoção desses elementos do suporte papel - processo específico da Conservação e Restauração -, a "eliminação de documentos" trata do descarte dos documentos que não são conservados/restaurados e nem arquivados. Desse modo, "eliminação" é um caso de NE com comportamento multidimensional. Na seção seguinte, comentaremos os casos de NE que apresentaram comportamento multidimensional e sua inserção na árvore de domínio.

TradTerm, São Paulo, v.37, n. 1, janeiro/2021, p. 294-329

Número Especial - Linguística de Corpus www.revistas.usp.br/tradterm 


\section{0 caráter multidimensional do NE}

Como já mencionado, segundo a TCT, o termo apresenta, além de um caráter poliédrico, um caráter multidimensional. Nesse sentido, um objeto, dentro de uma mesma disciplina, pode ser visto a partir de distintos pontos de vista. Por exemplo, Bojanoski (2018) em sua árvore de domínio localiza em dois diferentes lugares da estrutura conceitual da área os NE "conservação" e “limpeza”. Em seu Glossário de Conservação de obras em papel, a autora propõe as seguintes definições:

conservação (1) - denominação da área de conhecimento que abrange a conservação, a restauração e a conservação preventiva.

$(\ldots)$

Fonte: Glossário de Conservação de obras em papel (BOJANOSKI, 2018: 13).

conservação (2) - procedimentos que visam estabilizar os processos de deterioração ou degradação dos bens culturais. (3.2)

$(\ldots)$

Fonte: Glossário de Conservação de obras em papel (BOJANOSKI, 2018: 13).

limpeza (1) - (3.2.1)

Outra denominação: higienização

Fonte: Glossário de Conservação de obras em papel (BOJANOSKI, 2018: 22).

limpeza (2) - procedimento para remover as sujidades e componentes que comprometam a conservação e integridade da obra em papel. (3.3.1)

$(\ldots)$

Fonte: Glossário de Conservação de obras em papel (BOJANOSKI, 2018: 22).

Observamos que a autora mostra a multidimensionalidade desses termos com o uso da numeração (1) e (2), marcando que ocupam diferentes lugares na estrutura conceitual da área. Pelas definições, o termo “conservação" apresenta dois valores: um que denomina a área de

14 A autora insere na árvore limpeza (1) como sinônimo de higiene, cuja definição é "procedimento de limpeza realizado em obras, acervos ou nos ambientes de guarda de acervos para a retirada de componentes que comprometem a conservação dos bens culturais. (3.2.1)". (BOJANOSKI, 2018, p.21)

TradTerm, São Paulo, v.37, n. 1, janeiro/2021, p. 294-329

Número Especial - Linguística de Corpus

www.revistas.usp.br/tradterm 
conhecimento (1), e o outro que se refere aos procedimentos realizados na área. O mesmo vale para o termo "limpeza”, que se refere ora à limpeza como processo da conservação (3.2.1 da árvore de Bojanoski), ora ao processo de restauração (3.3.1 da árvore de Bojanoski).

Nos nossos dados, observamos o mesmo comportamento multidimensional entre os NE que coocorrem com os 5 NT analisados, como em "reconhecimento de obra”, “eliminação de documentos” e, como explicaremos mais detalhadamente, em "manter/manutenção de acervo" e “manter/manutenção de documento".

No momento da análise dos contextos, julgávamos que os valores do NE “manter/manutenção" combinado com ambos os NT ("acervo" e “documento") seriam os mesmos, bem como acreditávamos que a forma verbal manteria o mesmo valor da nominalizada “manutenção”. Entretanto, no caso de "manter acervo", identificamos o valor do verbo no sentido de "cuidar" do acervo à semelhança da função de gerenciar os arquivos, os museus e as bibliotecas. O mesmo valor foi constatado para a nominalização do NE, em "manutenção de acervo", conforme os contextos 3 e 4 do Corpus Papel.

3. Tendo em vista a importância dos espaços mencionados - museus, arquivos, bibliotecas - para a aquisição de informação e conhecimento e a conseqüente relevância de ser manter seus acervos em condições adequados para a utilização. (Corpus Papel Termisul).

4. O estabelecimento de rotinas de manutenção do acervo e o treinamento de funcionários devem ser desenvolvidos em âmbito institucional. (Corpus Papel Termisul).

Uma vez que, com base nos contextos, identificamos somente um valor para “manter/manutenção de acervo”, propusemos sua localização em 6.1.7, 
sob o núcleo conceitual da Administração (6) ${ }^{15}$, pois entendemos que se tratava de um processo referente à gestão dos acervos.

Entretanto, quando analisamos o NE “manter/manutenção” combinado com o NT “documento", constatamos que o valor do processo não era o mesmo que havíamos identificado com acervo, e que o NE apresentava mais de um valor nos diferentes contextos. Entendemos que esse também é um indício da restrição combinatória, pois, dependendo do NT com o qual se combina, há uma mudança no sentido do NE. Analisando as concordâncias, identificamos três diferentes valores para o NE "manter/manutenção":

a. "Manter/manutenção (1)" enquanto processo de "Conservação" (3.2.6);

b. "Manter/manutenção (2)" como processo de "reprodução" do documento, mas como forma de manter seu conteúdo (1.3.3.1);

c. "Manter/manutenção (3)" como processo de "não reprodução" do documento, isto é, como forma de manter seu formato (1.3.3.2).

Os fragmentos seguintes ilustram seus usos no corpus textual.

Manter/Manutenção (1) (3.2.6):

A conservação é relacionada com a ação da manutenção do documento por meios de intervenção no ambiente e sobre ele próprio. (Corpus Papel Termisul).

Manter/manutenção (2) (1.3.3.1):

Definir procedimentos e estratégias de gestão arquivística de documentos quando da criação, transmissão, e preservação de documentos em formatos digitais, com o objetivo de garantir a produção e manutenção de documentos fidedignos, autênticos, acessíveis, compreensíveis e preserváveis. (Corpus Papel Termisul).

${ }^{15}$ O núcleo conceitual 6, Administração, foi uma proposta de ampliação da árvore de domínio de Bojanoski (2018), apresentada na dissertação de Mestrado. Para mais informações sobre a criação desse núcleo conceitual, sugerimos a leitura de Arcos (2019: 119-124).

TradTerm, São Paulo, v.37, n. 1, janeiro/2021, p. 294-329

Número Especial - Linguística de Corpus

www.revistas.usp.br/tradterm 
Manter/manutenção (3) (1.3.3.2):

(...) Outra perspectiva de abordagem do valor - a noção de valor intrínseco - buscou justificar a manutenção de documentos na sua forma original, sendo um enfrentamento aos discursos de reprodução e de abandono como solução para a preservação de documentos. (Corpus Papel Termisul).

Para inserir os três valores identificados de "manter/manutenção" na árvore de domínio, seguimos a proposta de Bojanoski para indicar diferentes valores para as unidades com numerações. Por isso, identificamos “manter/manutenção (1)”, “manter/manutenção (2)” e “manter/manutenção (3)". Também nos baseamos na definição de Sager (1990) sobre as relações polivalentes, conforme explicado anteriormente.

Como já mencionado, as relações polivalentes consideram a posição de um conceito dentro de um sistema conceitual levando em conta suas diferentes atribuições. Para isso, também se deve levar em conta as relações desse conceito com os demais conceitos dentro da estrutura. Partindo dos contextos, propomos, então, a inserção das três dimensões do NE em (3.2.6), (1.3.3.1) e (1.3.3.2), conforme ilustram as figuras 11 e 12.

Figura 11- Inserção de "manter/manutenção" (1) na árvore de domínio de Bojanoski (2018) adaptada para o NT documento.

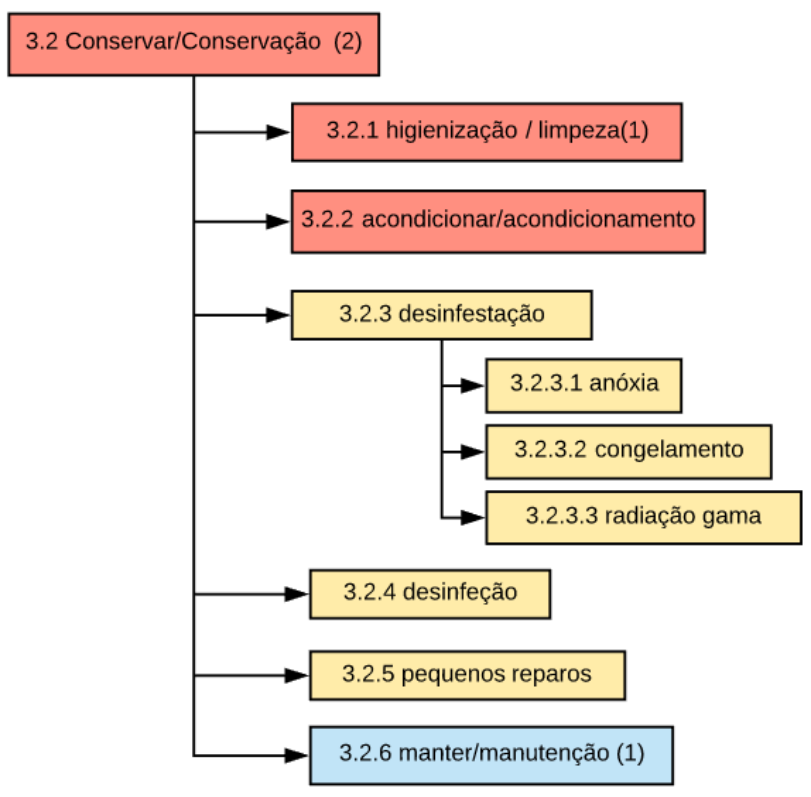

Fonte: $\operatorname{Arcos}(2019: 137)$

TradTerm, São Paulo, v.37, n. 1, janeiro/2021, p. 294-329

Número Especial - Linguística de Corpus www.revistas.usp.br/tradterm 
Inserimos “manter/manutenção (1)" em 3.2.6, subordinado ao hiperônimo "Conservar/Conservação", uma vez que, de acordo com o contexto de uso, a manutenção de documento constitui uma etapa da conservação. No caso de manter/manutenção (2) e (3), decidimos inseri-los subordinados ao hiperônimo "Meios de reprodução da informação (1.3.3)" ${ }^{16}$. A partir dele, inserimos “manter/manutenção (2)" em 1.3.3.1 e “manter/manutenção (3)" em 1.3.3.2. Uma vez que “manter/manutenção (2)" se referem ao processo de reprodução do documento, subordinamos a ele o NE “conversão" (1.3.3.1.1), e subordinamos à "conversão"17 os NE "digitalização" (1.3.3.3.1.1.1) e "microfilmagem" (1.3.3.1.1.2), posto que constituem processos de conversão de documentos, conforme indicamos na figura 12.

Figura 12 - Inserção de “manter/manutenção” (2) e (3) na árvore de domínio de Bojanoski (2018) adaptada para o NT "documento"

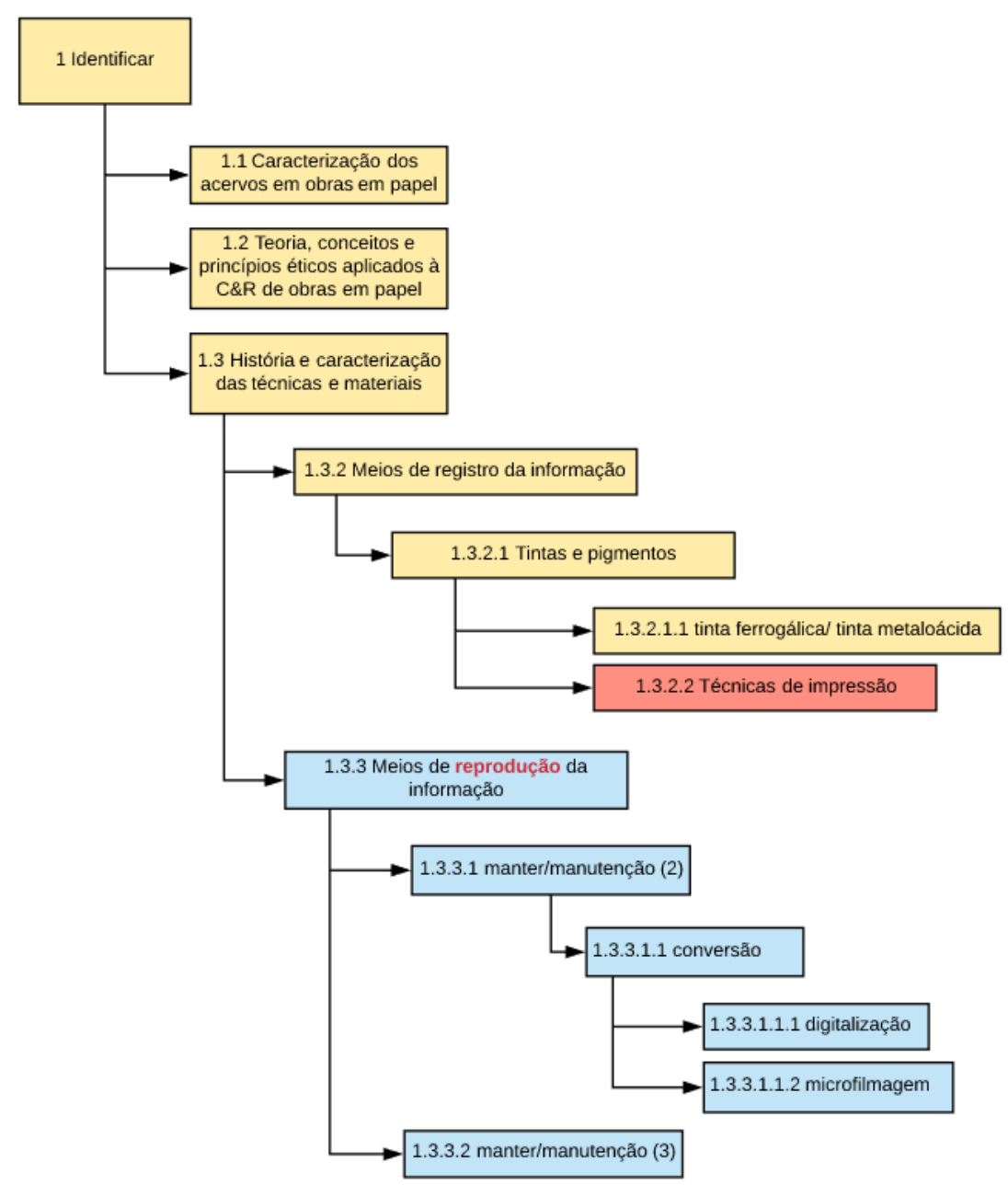

Fonte: $\operatorname{Arcos}(2019: 138)^{18}$.

${ }^{16}$ Para mais informações sobre a criação desse núcleo conceitual, sugerimos a leitura de Arcos (2019: 89).

17 A organização conceitual dos NE conversão, digitalização e microfilmagem, do mesmo modo que todos os demais casos, foi orientada pelos contextos de uso das UFE eventivas no corpus textual.

18 Retomamos as informações já apresentadas na nota de rodapé 10 sobre as legendas de cores: optamos por usar três cores como legenda a fim de marcar os dados extraídos: em

TradTerm, São Paulo, v.37, n. 1, janeiro/2021, p. 294-329

Número Especial - Linguística de Corpus

www.revistas.usp.br/tradterm 
Dessa forma, pela análise anterior, observamos um comportamento multidimensional do NE "manter/manutenção", que pode ser observado por diferentes perspectivas dentro do sistema conceitual da área. Levando em conta a proposta da TCT, em que o termo é um poliedro que pode ser acessado por diferentes facetas, poderíamos representar a multidimensionalidade do NE "manter/manutenção" quando combinado ao NT documento, como na figura 13 , em que cada faceta do poliedro corresponde a um valor diferente (dimensão).

Figura 13 - Multidimensionalidade do NE "manter/manutenção" combinado ao NT "documento"

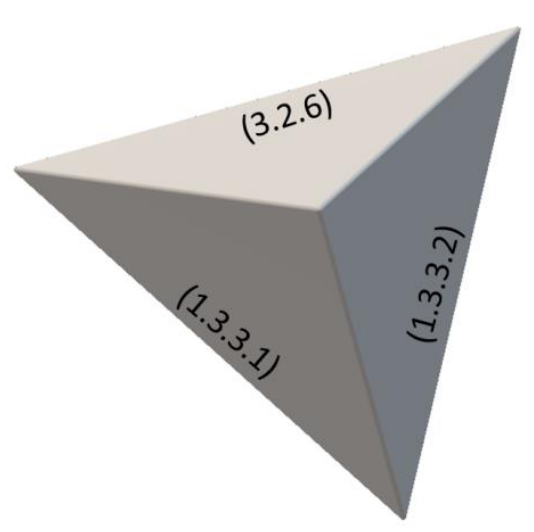

Fonte: $\operatorname{Arcos}(2019:$ 139)

Por outro lado, se considerássemos todos os valores que identificamos do NE "manter/manutenção", levando em conta o NT "acervo", por exemplo, seria possível acrescentar mais uma faceta ao poliedro, fazendo remissão a um valor descrito em 6.1 .7 (referente à gestão do acervo) na árvore de domínio (figura 14).

Finalmente, também observamos um comportamento multidimensional dos NE "utilizar/utilização" e "usar/uso", combinados com os NT "documento e papel", nas UFE eventivas: "usar documento" / "uso de documento"; "utilizar documento" / "utilização de documento"; "uso de papel”; "utilizar

vermelho estão os núcleos conceituais que identificamos no Corpus Papel e que já estavam inseridas na árvore de Bojanoski (2018); em amarelo estão os núcleos propostos pela autora, e que não identificamos no Corpus Papel, e, em azul, estão os núcleos conceituais que identificamos no Corpus Papel, mas que não estavam presentes na árvore de Bojanoski (2018).

TradTerm, São Paulo, v.37, n. 1, janeiro/2021, p. 294-329

Número Especial - Linguística de Corpus www.revistas.usp.br/tradterm 
papel”. Essas unidades apresentaram valores sinônimos nos contextos, denotando o uso de documento no sentido de "acesso" ou "consulta" ao documento, conforme exemplificam os seguintes contextos:

5. A preservação e conservação de livros e documentos são aspectos inerentes à própria utilização desses materiais $\mathrm{E}$, como é que se vai utilizar o museu, utilizar um documento de arquivos, um documento de biblioteca e seus congêneres, sem que este material esteja conservado? (Corpus Papel Termisul).

6. O tipo e a destinação de guarda, que são feitas por bibliotecas, arquivos, museus e centros de documentação, que utilizam os documentos (...). (Corpus Papel Termisul).

Sendo assim, inserimos os NE "usar"/ "uso" e "utilizar"/"utilização" num mesmo núcleo conceitual, subordinados ao hiperônimo de gestão (6.1), uma vez que entendemos que o acesso e a consulta aos documentos são processos subordinados às áreas afins da Arquivologia, Biblioteconomia e Museologia, no caso do corpus em análise. A figura 14 ilustra a inserção desses NE em (6.1.6).

TradTerm, São Paulo, v.37, n. 1, janeiro/2021, p. 294-329

Número Especial - Linguística de Corpus www.revistas.usp.br/tradterm 
Figura 14 - Inserção de "usar/uso" e "utilizar/utilização" na árvore de domínio de Bojanoski (2018) adaptada para o NT “documento".

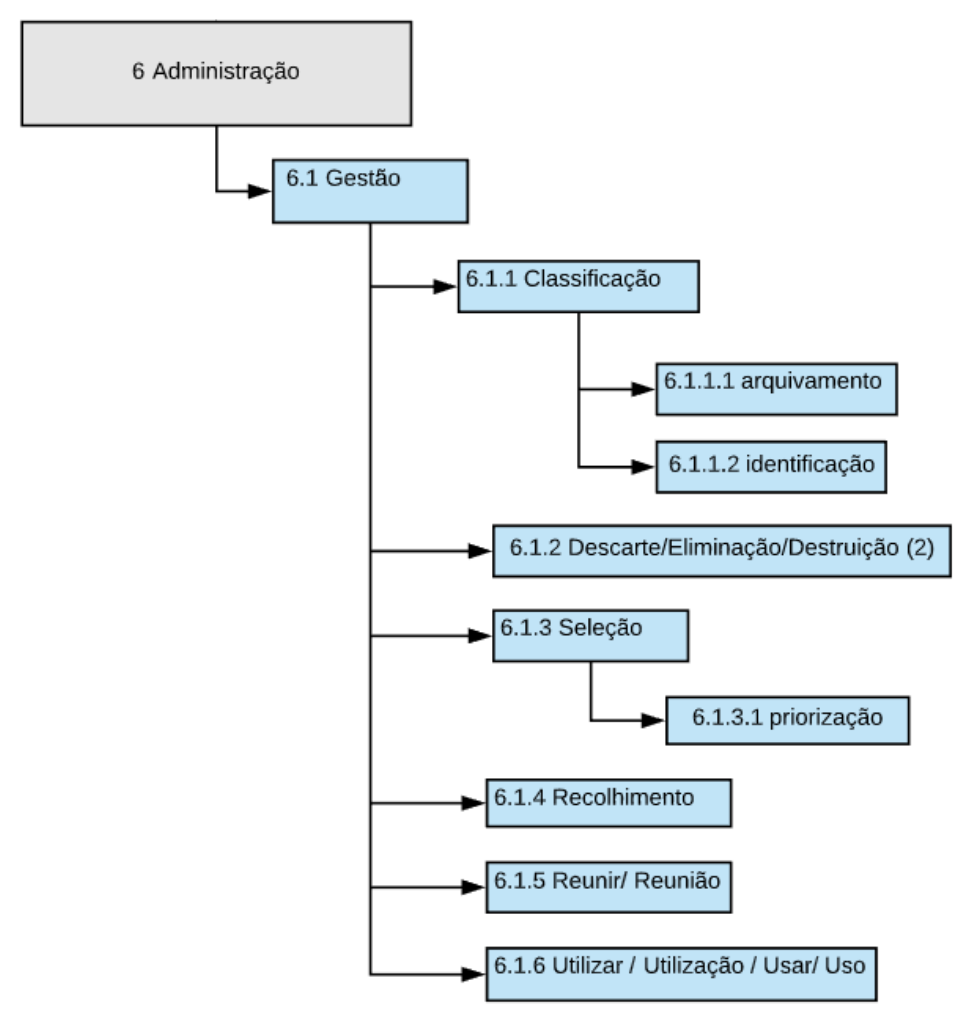

Fonte: $\operatorname{Arcos}(2019: 140)$

Contudo, quando avaliamos os contextos de uso dos NE "utilizar" e “uso" combinados com o NT “papel”, identificamos que esse NT sofre uma mudança de valor dependendo do NE com o qual se combina. Assim, quando “papel" se combina com o NE "uso", refere-se ao suporte que será conservado/restaurado. Os contextos a seguir exemplificam o caso.

7. Castro (1969: 19) cita que o uso do papel se daria, principalmente, em trabalhos de segunda linha; livros editados com o material receberiam encadernações mais medíocres, e o pergaminho seria reservado às obras mais importantes. (Corpus Papel Termisul).

Entretanto, quando combinado com o NE verbal "utilizar", o NT papel assume o valor de material utilizado durante o processo de restauração, e não mais o valor do suporte que será conservado ou restaurado. Os contextos ilustram o caso.

8. Impedidos de utilizar um papel de trapo de algodão de boa qualidade, cuja permanência já está devidamente comprovada (...) (Corpus Papel Termisul).

TradTerm, São Paulo, v.37, n. 1, janeiro/2021, p. 294-329 Número Especial - Linguística de Corpus www.revistas.usp.br/tradterm 
9. Seguiu-se o processo de secagem natural, utilizando papel pardo na absorção da umidade (...) (Corpus Papel Termisul).

10. (...) utilizar papéis mata-borrão ou absorventes para o processo de secagem. (Corpus Papel Termisul).

11. Se podia obter por contato quantas cópias se desejasse, utilizando papel cianográfico. (Corpus Papel Termisul).

12. Procedendo pequenos reparos (remendos), utilizando papel japonês ou outro alcalino(...). (Corpus Papel Termisul).

13. Para o enxerto, alguns autores utilizam o próprio papel translúcido visando à recomposição da parte faltante (...). (Corpus Papel Termisul).

Em todos os contextos, observamos que o NT "papel” refere-se aos diferentes tipos de papel que são empregados no processo da Restauração, assumindo a forma de termo sintagmático em todos os casos, especificando o tipo de papel (como material): "papel de trapo”, “papel pardo”, “papel mata-borrão”, “papel cianográfico”, “papel japonês”, “papel translúcido”. Entendemos que esses NT são diferentes do NT "papel" (suporte conservado/restaurado) que é objeto da conservação e restauração.

Por isso, chamamos a atenção para o comportamento dos NE “utilizar/uso". Enquanto esses NE apresentam um comportamento equivalente quando combinados com o NT “documento”, como já explicamos, quando se combinam com o NT “papel” não somente mudam de valor passam a ter o sentido de "aplicar", no caso de "utilizar", e de "escolher", no caso de "uso" -, mas também restringem a seleção do NT. Nesse caso, a restrição combinatória demonstra que, dependendo do NE que se combina com o NT, este sofre uma mudança em seu valor.

Também entendemos que essa restrição combinatória dos NE “uso" e "utilizar" possa estar atrelada a sua estrutura morfossintática. Diferentemente da forma nominal (uso), a forma verbal (utilizar) parece expressar mais fortemente uma ação, o que poderia justificar sua combinação com determinados NT para expressar os processos realizados durante a restauração. Contudo, reconhecemos que seria necessário analisar uma TradTerm, São Paulo, v.37, n. 1, janeiro/2021, p. 294-329 Número Especial - Linguística de Corpus www.revistas.usp.br/tradterm 
amostra maior de dados para comprovar que a estrutura morfossintática pode ter incidência sobre a restrição combinatória.

Com base nessa análise, propusemos a inserção de "uso" e "utilizar" na árvore de domínio do NT "papel” sob diferentes núcleos conceituais. Subordinamos o NE “utilizar" ao hiperônimo 3.3 Restauração, em 3.3.15. Já o NE "uso" foi subordinado a "1 Identificar > 1.3 História e caracterização das técnicas e materiais > 1.3.1 Suportes > 1.3.1.1 papel > 1.3.1.1.5 uso de papel”. As figuras 15 e 16 ilustram as inserções. 
Figura 15 - Inserção de "utilizar” na árvore de domínio de Bojanoski (2018) adaptada para o NT "papel”.

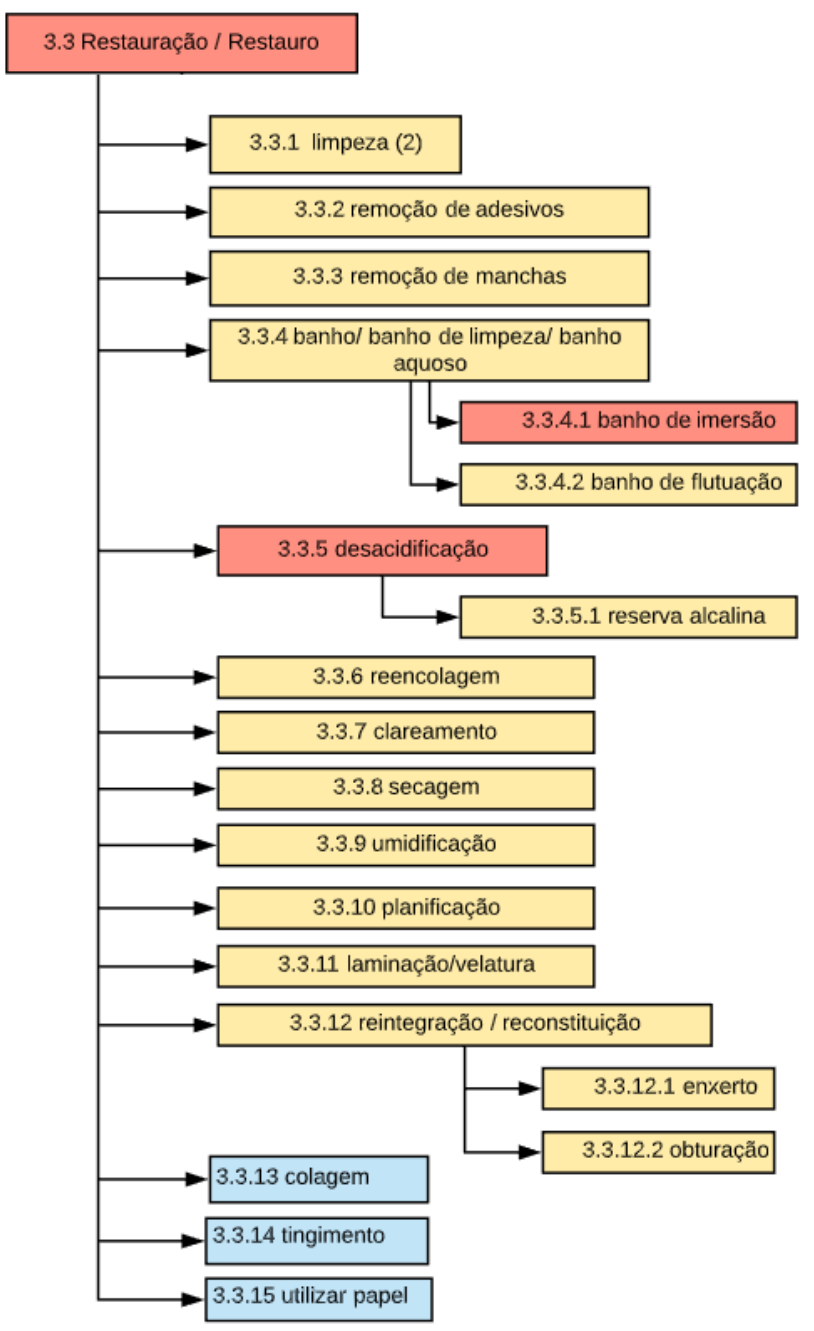

Fonte: $\operatorname{Arcos}(2019: 143)$

TradTerm, São Paulo, v.37, n. 1, janeiro/2021, p. 294-329

Número Especial - Linguística de Corpus

www.revistas.usp.br/tradterm 
Figura 16 - Inserção de “uso” na árvore de domínio de Bojanoski (2018) adaptada para o NT "papel”.

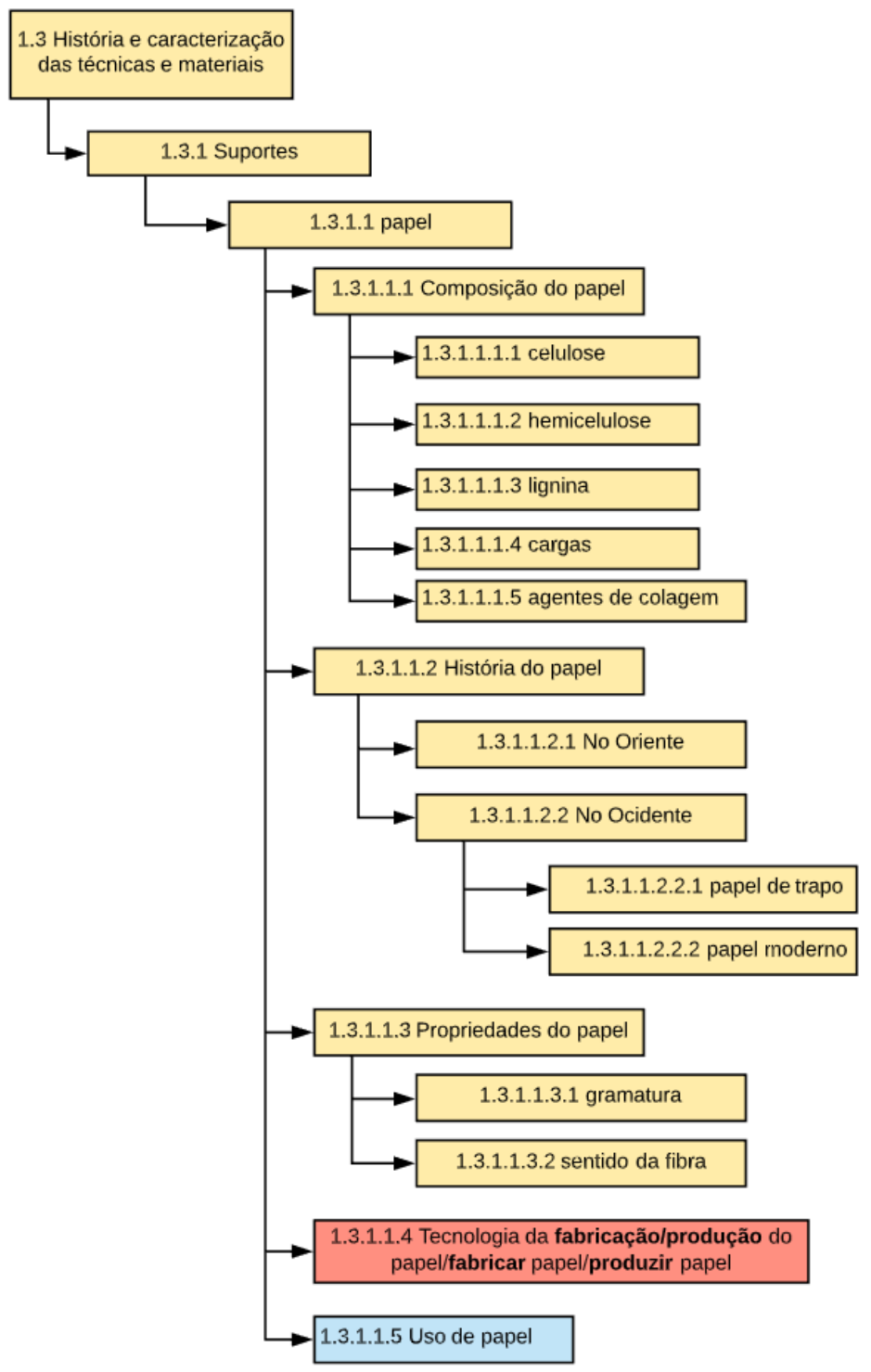

Fonte: $\operatorname{Arcos}(2019: 144)$

\section{Considerações finais}

A partir da identificação e extração de UFE eventivas do Corpus Papel da área de Conservação e Restauração e de sua análise qualitativa foi possível observar mais detidamente o fenômeno da restrição combinatória entre os elementos nucleares (NT e NE) que constituem esse tipo de fraseologia especializada, bem como seu caráter multidimensional.

TradTerm, São Paulo, v.37, n. 1, janeiro/2021, p. 294-329 Número Especial - Linguística de Corpus 
Em relação ao fenômeno da restrição combinatória, identificamos que são os processos (NE) que se combinam de maneira restrita com os termos (NT), sugerindo que, no caso das UFE analisadas, o fenômeno parece ter maior peso sobre o NE (como, por exemplo, nos casos de "desmonte" e "planificação de obra", "amarelecimento", "colagem" e "envelhecimento de papel"). Acreditamos que esse tipo de resultado fortalece a importância de estudos que se debrucem sobre o NE, sobretudo no que se refere à identificação de equivalentes em outras línguas para a compilação de produtos terminográficos. Uma vez que a restrição combinatória parece estar mais marcada pelo NE do que pelo NT, identificar o equivalente adequado do processo em outras línguas pode ser tão importante como identificar o termo adequado.

Quanto à multidimensionalidade, identificamos, a partir dos resultados, que esse não é um princípio que se aplica apenas aos termos, mas também aos NE - verbos e nominalizações. Observamos duas situações de multidimensionalidade. A primeira se refere ao caso do NE "manter/manutenção" que, quando combinado com o NT "acervo", apresentou um valor referente à administração, mas quando combinado com o NT "documento" apresentou três diferentes valores: "manutenção" referente à "administração", "manutenção de conteúdo", a partir da reprodução de documento, e "manutenção de formato", a partir da não reprodução do documento.

Observamos, ainda, os diferentes valores para os NE "usar/uso" e "utilizar/utilização", cujos sentidos na língua comum são sinônimos, mas que no corpus de estudo apresentaram não somente valores diferentes como também modificaram o valor do NT "papel”, dependendo da estrutura morfossintática na qual ocorria (nominalização ou verbo). Desse modo, enquanto a forma nominal "uso" em uso de papel apresentou o sentido de "emprego do suporte papel" - que é o objeto de conservação e restauração -, sua forma verbal "utilizar papel" apresentou o sentido de "empregar o papel" durante os processos de restauração. Nesse caso, "utilizar" não somente se refere a um processo diferente, como também muda o valor do NT, que passa a ser um material usado na restauração (papel mata-borrão, papel japonês,

TradTerm, São Paulo, v.37, n. 1, janeiro/2021, p. 294-329 Número Especial - Linguística de Corpus www.revistas.usp.br/tradterm 
papel pardo etc.). Neste caso, destacamos não somente a multidimensionalidade dos NE, mas também da poliedricidade do NT gerada por essa restrição combinatória de ordem morfossintática.

Finalmente, retomamos e ressaltamos a importância do corpus de estudo para a identificação das UFE eventivas da área e para o estudo dos fenômenos da restrição combinatória e da multidimensionalidade. Sem o levantamento das concordâncias e dos contextos de uso a partir de um corpus de estudo compilado com base em critérios bem definidos, seria inviável realizar a análise aprofundada que nos permitiu chegar a resultados tão ricos. Tais resultados não somente ajudaram a explicar a constituição terminológica da área da Conservação e Restauração, como também permitiram realizar a análise e entender de forma mais aprofundada as UFE eventivas. Portanto, reafirmamos e destacamos a importância da Linguística de Corpus em todas as etapas metodológicas seguidas na presente pesquisa e na obtenção de resultados que permitiram entender melhor não apenas os fenômenos analisados - restrição combinatória e multidimensionalidade - na área de Conservação e Restauração, mas também a sua interdisciplinaridade com outras áreas afins, como a Arquivologia, Biblioteconomia e Museologia.

TradTerm, São Paulo, v.37, n. 1, janeiro/2021, p. 294-329

Número Especial - Linguística de Corpus www.revistas.usp.br/tradterm 


\section{Referências}

ARcos, M. Identificação e análise de UFE eventivas na área da conservação e restauração de bens culturais móveis em suporte papel. 2019. $166 \mathrm{f}$. Dissertação (Mestrado em Lexicografia, Terminologia e Tradução) Instituto de Letras da Universidade Federal do Rio Grande do Sul, Porto Alegre. 2019.

BEJOINT, H.; THOIRON, P. Macrostructure et microstructure dans un dictionnaire de collocations en langue de spécialité. Terminologie et traduction, 2-3. Bruxelas: Comisión des Communautés Européennes, Service de Traductions, 1992, pp. 513- 522.

BERBER SARDINHA, T. Lingüística de Corpus: histórico e problemática. DELTA, v. 16, $n^{\circ}$ 2. pp. 323-367, 2000.

BeVILACQUA, C. R. Unidades Fraseológicas Especializadas Eventivas: descripción y reglas de formación en el ámbito de la energía solar. 2004. $241 \mathrm{f}$. Tese (Doutorado em Linguística Aplicada) - Instituto Universitário de Linguística Aplicada (IULA), Universidade Pompeu de Fabra, Barcelona. 2004.

BLAIS, E. La phraséologie. Une hypothèse de travail. Terminologies Nouvelles, 10. Bruxelas: RINT, 1993, pp. 50-56.

BoJanoskI, S. Terminologia em Conservação de bens culturais em papel: produção de um glossário para profissionais em formação. Orientador: Cleci Regina Bevilacqua. 2018. 292 f. Tese (Doutorado em Memória Social e Patrimônio Cultural) - Programa de Pós-Graduação em Memória Social e Patrimônio, Universidade Federal de Pelotas, Pelotas, 2018.

CABRÉ, M. T. Terminología y lingüística: la teoría de las puertas. Estudios de lingüística del español, V. 16. 2002. Disponível em: http://elies.rediris.es/elies16/Cabre.html. Acesso em: 8 de agosto de 2019.

CABRÉ, M. T. La terminología: representación y comunicación. Elementos para una teoría de base comunicativa y otros artículos. $1^{\text {a }}$ ed. Barcelona: Universitat Pompeu Fabra, Institut Universitari de Lingüística Aplicada. 1999.

HAUSMANn, F. J. (1990). Le dictionnaire de collocations. In: HaUsmann, F. J. et al (Org.). An International encyclopedia of lexicography. Vol. 1. Berlin, New York: Walter de Gruyter. 1990. pp: 1010-1019.

KJAER, A. L. Phraseology research: state-of-the-art: methods of describing word combinations in language for specific purposes. Terminology science and research: Journal of International Institute for Terminology Research, v. 1, n. 1-2. pp. 3-20, 1990.

TradTerm, São Paulo, v.37, n. 1, janeiro/2021, p. 294-329

Número Especial - Linguística de Corpus www.revistas.usp.br/tradterm 
L'HOMme, M.-C.; Bertrand, C. Specialized Lexical Combinations: should they be described as collocations or in terms of selectional restrictions? Ninth EURALEX International Congress. Proceedings of the Ninth Euralex International Congress. Stuttgart: Universitat Stuttgart. 2000. pp. 4974-4506.

SAGER, J. C. Curso práctico sobre el procesamiento de la terminología. Madrid: Fundación Germán Sánchez Ruipérez, 1990.

Sanchez, A. Definicion e historia de los corpus. In: SAnchez, A. et al (org.). CUMBRE - Corpus Linguistico de Espanol Contemporaneo. Madrid: SGEL, 1995, pp. 7-24.

Recebido em: 18/03/2020

Aceito em: 17/09/2020

Publicado em janeiro de 2021

TradTerm, São Paulo, v.37, n. 1, janeiro/2021, p. 294-329

Número Especial - Linguística de Corpus

www.revistas.usp.br/tradterm 